\title{
Clinical evolution of sacral stress fractures: influence of additional pelvic fractures
}

\author{
P Peris, N Guañabens, F Pons, R Herranz, A Monegal, X Surís, J Muñoz-Gómez
}

\begin{abstract}
Objectives-To evaluate the clinical evolution of sacral stress fractures in relation to the scintigraphic pattern and the presence of additional pelvic fractures.

Methods-This was a retrospective study of 14 patients with sacral fractures.

Results-Six patients had additional pelvic fractures. Four bone scintigraphic patterns were found. The resolution of symptoms was longer in patients with associated pelvic fractures (30 weeks $v$ three weeks). No relation was found between the bone scintigraphic pattern and the time of evolution.

Conclusion-Associated pelvic fractures delay the resolution of symptoms in patients with sacral fractures, regardless of scintigraphic pattern.
\end{abstract}

(Ann Rheum Dis 1993; 52: 545-547)

Stress fractures are injuries that occur as a result of repeated cyclic loading of the bone. Depending on the state of the bone affected, these fractures are divided into two types: fatigue fractures, which occur in bone with normal elastic resistance which has been loaded to an unaccustomed degree, and insufficiency fractures, which occur in weakened bone. ${ }^{1}$ Several pathological processes may decrease the elastic resistance of bone, and predispose it to the development of insufficiency fractures. Osteoporosis is one of the most common associated conditions. Fractures related to osteoporosis commonly affect the spine, pelvis, and femur. Sacral fractures are not uncommon, however, they may be overlooked. ${ }^{2}$ Characteristic scintigraphic patterns of this fracture have been previously described. ${ }^{34}$ These fractures frequently occur in elderly women with pronounced osteopenia, in whom histories of previous injury are usually absent. ${ }^{5-7}$ Data on clinical symptoms, particularly on clinical outcome, are scarce, and no reports have previously been published on the relation between the scintigraphic pattern of sacral fracture and the time to clinical outcome, or with the presence of additional pelvic fractures.

The aim was to evaluate the clinical evolution of sacral fractures in relation to the scintigraphic pattern and the presence of additional pelvic fractures.
Patients and methods

Over a period of 34 months (March 1989 to January 1992), 14 patients (12 women, two men) were diagnosed as having sacral fractures. The average age was 65 years (range 48-80 years). Their clinical records were reviewed to determine their presenting symptoms, the risk factors for fracture, and the clinical evolution. Special attention was paid to the chronological course of clinical symptoms. Sacral plain film radiography and bone scintigraphy were performed on all patients and, in five, computed tomography (CT) was also used. Lumbar bone mineral density (BMD) was measured by dual photon absortiometry (Lunar-DP3) in 11 patients.

The diagnosis of sacral fracture was established on the basis of the presence of compatible clinical data confirmed by one or more of the diagnostic methods, and a favourable outcome. Osteoporosis was defined as a bone mineral density of the lumbar spine two standard deviations or more below the young normal values, ${ }^{8}$ or by the presence of atraumatic spinal fractures, or both.

\section{Results}

The most common presenting symptom was diffuse low back pain, accompanied in five patients by hip, buttock, or thigh pain. Pertinent physical findings were limited to tenderness on palpation of the sacrum and decreased range of low back motion. Moreover, five patients, those with additional pelvic fractures, had groin pain. Five patients had a previous history of minor trauma, usually a fall. None referred to previous unusual activity as a causative factor.

All patients were diagnosed as having osteoporosis. Characteristics of the patients are shown in the table. Lumbar BMD was measured in 11 patients, all of whom had osteoporosis. In addition, the lumbar BMD was below the fracture threshold in all cases. In one patient a bone biopsy discounted concomitant osteomalacia.

A retrospective review showed abnormalities on radiographs in nine cases, consisting of disruption, deformity or sclerosis of the sacral arcuate lines (fig 1), but the abnormalities were often overlooked on the original reading. In five patients, CT was performed, confirming a sacral fracture in all. Other fractures, occurring either before or at the time of the sacral fracture, were common. Compression fractures of the spine were present in 10 
Characteristics of the patients

\begin{tabular}{|c|c|c|c|c|}
\hline Sex/Age & Diagnosis & $\begin{array}{l}\text { Scintigraphic } \\
\text { pattern }^{\star}\end{array}$ & $\begin{array}{l}\text { Other } \\
\text { fractures }\end{array}$ & $\begin{array}{l}\text { Resolution } \\
\text { of symptoms } \\
\text { (weeks) }\end{array}$ \\
\hline M/55 & $\begin{array}{l}\text { Cryptogenic cirrhosis } \\
\text { Liver transplant steroid therapy }\end{array}$ & c & $\begin{array}{l}\text { Spinal } \\
\text { Costal }\end{array}$ & 3 \\
\hline $\mathrm{F} / 73$ & Postmenopausal osteoporosis & $\mathrm{d}$ & Spinal & 4 \\
\hline $\mathrm{F} / 60$ & Primary biliary cirrhosis & a & $\begin{array}{l}\text { Spinal } \\
\text { Costal } \\
\text { Pelvis }\end{array}$ & 40 \\
\hline $\mathrm{F} / 70$ & Postmenopausal osteoporosis & b & $\begin{array}{l}\text { Spinal } \\
\text { Costal } \\
\text { Pelvis }\end{array}$ & 32 \\
\hline $\mathrm{F} / 73$ & Temporal arteritis steroid therapy & c & Spinal & 4 \\
\hline $\mathrm{F} / 54$ & $\begin{array}{l}\text { Post-hepatitic cirrhosis } \\
\text { Liver transplant steroid therapy }\end{array}$ & c & & 2 \\
\hline $\mathrm{F} / 78$ & Senile osteoporosis & a & $\begin{array}{l}\text { Pelvis } \\
\text { Femur }\end{array}$ & 32 \\
\hline M/48 & Chronic alcoholism & $\mathrm{d}$ & $\begin{array}{l}\text { Spinal } \\
\text { Pelvis }\end{array}$ & 24 \\
\hline $\mathrm{F} / 58$ & $\begin{array}{l}\text { Primary biliary cirrhosis } \\
\text { Liver transplant steroid therapy }\end{array}$ & $\mathrm{d}$ & $\begin{array}{l}\text { Spinal } \\
\text { Femur }\end{array}$ & 2 \\
\hline $\mathrm{F} / 65$ & Polymyalgia rheumatica steroid therapy & a & Spinal & 4 \\
\hline $\mathrm{F} / 80$ & Senile osteoporosis & b & $\begin{array}{l}\text { Costal } \\
\text { Coccyx }\end{array}$ & 16 \\
\hline $\mathrm{F} / 67$ & Postmenopausal osteoporosis & a & Spinal & 4 \\
\hline $\mathrm{F} / 63$ & Primary biliary cirrhosis & b & $\begin{array}{l}\text { Spinal } \\
\text { Costal }\end{array}$ & 2 \\
\hline $\mathrm{F} / 74$ & Senile osteoporosis & c & $\begin{array}{l}\text { Spinal } \\
\text { Pelvis }\end{array}$ & 36 \\
\hline
\end{tabular}

^See text for description of patterns.

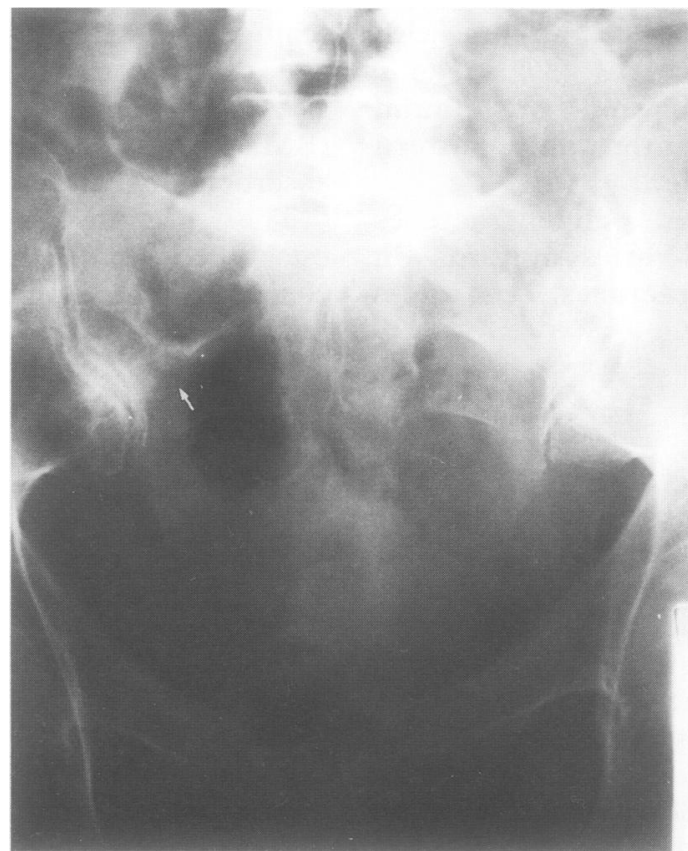

Figure 1 Anteroposterior radiograph of the pelvis showing discontinuity of the first right sacral arc (arrow).

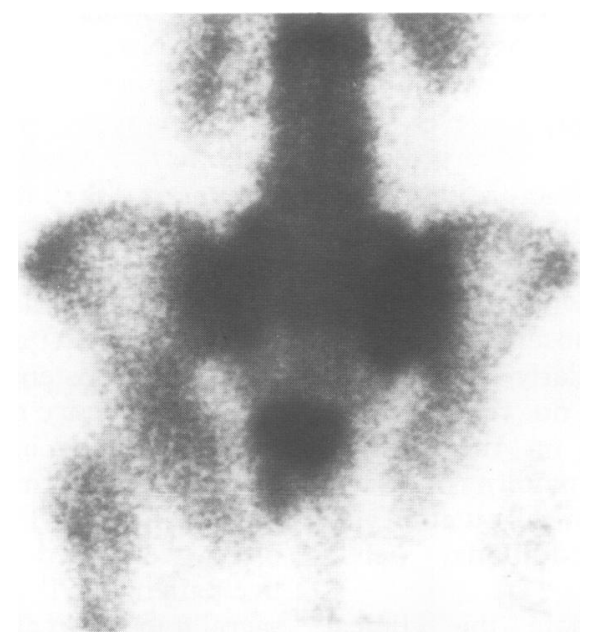

Figure 2 Posterior view of a bone scan of the pelvis showing an increased uptake of isotope in both sacral alae and in the body of sacrum, giving a characteristic butterfly shaped pattern. patients, fractures of the pubis and ischium were found in five, costal fractures in five, and fractures of the femoral neck and coccyx in one each. All but one of the additional pelvic fractures were diagnosed on the original reading, the one overlooked being a parasymphiseal fracture which was initially diagnosed by bone scintigraphy.

In all cases bone scintigraphy was performed, and all showed areas of increased radioisotope uptake in the sacrum. The scintigraphic abnormalities representing sacral fractures appeared in four patterns (table): $(a)$ in the body of the sacrum and both sacral ala (four cases), giving an $\mathrm{H}$ or butterfly shaped appearance (fig 2); (b) in the body of the sacrum and one sacral ala (three cases); (c) in both sacral ala (four cases); and $(d)$ in a single ala (three cases, one of them with focal activity).

Five patients had concomitant pelvic fractures. Two of them showed the first pattern, and the others, the second, third and fourth patterns. One patient had a simultaneous coccyx fracture; this fracture was also considered to be an additional pelvic fracture. All of the pelvic fractures could be evaluated on the original scintigraphic scan.

Clinical follow up was carried out between six and 26 months (mean 16 months) after presentation. The average time from onset to resolution of the symptoms was 15 weeks (range 2-40), being much longer in patients with associated pelvic fractures than in patients with sacral fractures only (30 weeks (range 16-40 weeks) $v$ three weeks (range 2-4 weeks)). No relation was found between the scintigraphic patterns and the average time of resolution of symptoms. Repeated bone scans were performed in two patients, two and seven months after the initial abnormal scan, showing a decreased uptake in the sacrum. All patients were treated with bedrest and nonsteroidal anti-inflammatory drugs, and in eight cases subcutaneous calcitonin was added to the treatment. Four of these patients had associated pelvic fractures. The mean time to clinical outcome in patients with calcitonin treatment was 18 weeks, whereas in the remaining patients it was nine weeks.

\section{Discussion}

The present study clearly shows that additional pelvic fractures increase the time to clinical outcome. The time from onset to resolution of the symptoms in the patients with only sacral fractures was three weeks. In patients with associated pelvic fractures, however, the average time of resolution of symptoms was much longer, being 30 weeks. These results agree with previous reports, in which the average time to clinical outcome for sacral fractures varied from one to 12 months. ${ }^{5-7}$ In these reports, however, the role of additional pelvic fractures was not considered. Moreover, the clinical course of isolated stress fractures of the pubic ramus is shorter, between six and 10 weeks, than that associated with sacral fractures. ${ }^{9}$ 
In accordance with previous reports, postmenopausal and senile osteoporosis were the predisposing conditions in most patients ${ }^{5-7}$ and, as has been recently described, liver transplantation was the second most common associated factor. ${ }^{10}$ Clinical symptoms in this series varied from moderate to severe low back pain and, additionally, all patients with pubic fractures had groin pain. There were no signs of radiculopathy, which rarely occurs. ${ }^{4}$

Sacral insufficiency fractures are difficult to diagnose for several reasons. The findings on radiographs are very subtle and easily overlooked, requiring a careful examination. The irregularity in the arcuate lines is a sensitive indicator of a possible fracture. ${ }^{11} 12$ Another, and probably the most important reason, is the lack of awareness of this fracture. Jackson et al $^{11}$ reported that, in a series of 50 patients with pelvic ring fractures, concomitant sacral fractures occurred in $72 \%, 61 \%$ of these being overlooked at the time of the initial radiological interpretation. In our series, five of the 14 patients had associated pelvic fractures, and one patient had a fractured coccyx. In all but one, both processes occurred simultaneously.

Bone scintigraphy is a sensitive test for skeletal trauma. Fractures may be detected as early as one day after their occurrence and, even in older patients, the bone scan is usually abnormal at the fracture site within 72 hours of injury. Areas of increased isotope uptake may persist for two or more years, depending on the location and type of bone fracture. ${ }^{13}$

Radionuclide bone scans of sacral fractures may have several different appearances. In accordance with other authors, ${ }^{34}$ we found four different scintigraphic patterns, the most characteristic one being butterfly shaped. Unilateral or bilateral increased isotope uptake in the sacral alae create less specific patterns, which may raise problems in distinguishing between fractures and infectious or inflammatory processes of the sacrum. ${ }^{34}$ These two processes, however, may be easily differentiated by CT which, in doubtful cases, is the most specific method of diagnosis. ${ }^{14}$ In our patients, no relation was found between the scintigraphic patterns of sacral fractures and the time to clinical outcome, which was probably owing to the presence of concomitant pelvic fractures.

The recommended treatment of sacral stress fractures has several elements: reduced physical activity, analgesic treatment, and in some cases the initiation of treatment for associated osteoporosis. ${ }^{7}$ In our patients, the treatment consisted of management to reduce pain (bedrest, analgesics) and to treat the associated osteoporosis. The type of treatment did not seem to affect the final outcome significantly. Eight of our patients received additional calcitonin therapy without a significant improvement; however, it is difficult to evaluate this data because this is a retrospective study, and patients on calcitonin therapy seemed to be more affected.

In conclusion, the time to resolution of symptoms in patients with sacral fractures is not related to the sacral scintigraphic pattern, the concomitant fractures in the pelvic ring being the main factor influencing the clinical outcome.

1 Renner J B. Pelvic insufficiency fractures. Arthritis Rheum 1990; 33: 426-70

2 Cooper K L, Beabout J W, Swee R G. Insufficiency fractures of the sacrum. Radiology 1985; 156: 15-20.

3 Ries T. Detection of osteoporotic sacral fractures with radionuclides. Radiology 1983; 146: 783-5.

4 Schneider R, Yacovone J, Ghelman B. Unsuspected sacral fractures: detection radionuclide bone scanning. $A m \mathcal{F}$ Roentgenol 1985; 144: 337-41.

5 Cotty Ph, Fouquet B, Mezengue C, et al. Fractures du sacrum par insuffisance osseuse. A propos de 10 cas. $\mathcal{F}$ Neuroradiol 1989; 16: 160-71.

6 De Smet A A, Neff J R. Pubic and sacral insufficiency fractures: clinical course and radiologic findings. $A m \mathcal{F}$ Roentgenol 1985; 145: 601-6.

7 Rawlings III C E, Wilkins R H, Martinez S, Wilkinson R $\mathrm{H}$. Osteoporotic sacral fractures: a clinical study. Neurosurgery 1988; 22: 72-6.

8 Nordin B E C. The definition and diagnosis of osteoporosis. Calcif Tissue Int 1987; 40: 57-8.

9 Paulov H, Nelson T, Warren R, Torg J, Burstein A. Stress fractures of the pubic ramus. $f$ Bone foint Surg 1982; 64-A: $1020-5$

10 Peris $P$, Navasa $M$, Guanabens $N$, et al. Sacral stress fracture after liver transplantation. Br $\mathcal{f}$ Rheumatol. In press.

11 Jackson H, Kam J, Harris J H, Harle T S. The sacral arcuate lines in upper sacral fractures. Radiology 1982; 145: lines

12 Northrop C H, Eto R T, Loop J W. Vertical fracture of the sacral ala. Significance of the non-continuity of the anterior superior sacral foraminal line. Am $\mathcal{F}$ Roentgenol 1975; 124: 102-6.

13 Martin P. The appearance of bone scans following fractures, including immediate and long-term studies. $\mathcal{f} \mathrm{Nucl} \mathrm{Med}$ 1979; 20: 1227-31

14 Davies A M, Evans N S, Struthers G R. Parasymphyseal and associated insufficiency fractures of the pelvis and sacrum. Br f Radiol 1988; 61: 103-8. 